\title{
Coyote's Tale on the Old Oregon Trail: Challenging Cultural Memory through Narrative at the Tamástslikt Cultural Institute
}

Jackson B. Miller

Linfield College

Follow this and additional works at: https://digitalcommons.linfield.edu/commfac_pubs

Part of the Critical and Cultural Studies Commons, and the Indigenous Studies Commons

\section{DigitalCommons@Linfield Citation}

Miller, Jackson B., "Coyote's Tale on the Old Oregon Trail: Challenging Cultural Memory through Narrative at the Tamástslikt Cultural Institute" (2005). Faculty Publications. Accepted Version. Submission 3.

https://digitalcommons.linfield.edu/commfac_pubs/3

This Accepted Version is protected by copyright and/or related rights. It is brought to you for free via open access, courtesy of DigitalCommons@Linfield, with permission from the rights-holder(s). Your use of this Accepted Version must comply with the Terms of Use for material posted in DigitalCommons@Linfield, or with other stated terms (such as a Creative Commons license) indicated in the record and/or on the work itself. For more information, or if you have questions about permitted uses, please contact digitalcommons@linfield.edu. 
Coyote's Tale on the Old Oregon Trail:

Challenging Cultural Memory through Narrative at the Tamástslikt Cultural Institute

Jackson B. Miller

Jackson B. Miller is an Associate Professor of Theatre and Communication Arts and Director of Forensics at Linfield College. An earlier version of this paper was presented at the 2005 Western States Communication Association convention in San Francisco. The author wishes to thank Michael Bowman, Kathleen Spring, Nathan Stucky, and two anonymous reviewers for their helpful comments on earlier drafts of this essay. Correspondence to: Jackson B. Miller, Associate Professor, Department of Theatre and Communication Arts, Linfield College, 900 SE Baker St., McMinnville, OR 97128-6894, USA. Email: jmiller@linfield.edu

\begin{abstract}
This essay examines the oppositional narratives presented in a Native American museum in order to explore the efficacy of narrative as both a strategy for resistance to hegemonic narratives of the settling of the West and a medium for sharing culture. The positioning of the museum visitor as co-participant in the museum's narratives is also considered, with a particular focus on the relationships among narrator, story, and audience. Finally, the narrative of tribal life presented in the museum is evaluated for its potential as a vehicle for both cultural change and continuity.
\end{abstract}

Keywords: narrative, Native American, museum, counter-narrative, oppositional discourse 
Just a few miles outside Pendleton, Oregon, where wagon trains full of settlers (or perhaps unsettlers) once rumbled by in the thousands, sits the Tamástslikt Cultural Institute, "the only Indian-run, Indian-owned interpretative center along the entire length of the old Oregon Trail" (Egan). Tamástslikt is operated by the Confederated Tribes of the Umatilla Indian Reservation, a group consisting of individuals from the Cayuse, Umatilla, and Walla Walla tribes. The center is, according to its web site, "more than a visitor attraction" because it "helps document and preserve traditions and practices that distinguish the Confederated Tribes from any other peoples." As Alice Feldman notes, "American Indians have had little voice in the mainstream interpretation of their cultures and articulations of the historical record" (211); Tamástslikt is an attempt to reverse this trend.

The country is in the midst of an ongoing celebration of the bicentennial of the Lewis and Clark expedition, and in this climate narratives from other perspectives are often lost or distorted. Historian Rick Harmon observes, "[w]hen passing on, from generation to generation, a sense of what came before, the 'winners' tend not so much to tell the story of what happened as [to] explain, implicitly, why it had to happen the way it did" (117). While the story of the Lewis and Clark expedition and the "conquering of the West" is, for many, an affirmation of the "pioneer spirit" that makes America strong, the stories, traditions, and ways of life of the many Native American tribes in the Pacific Northwest were lost in the wake of the wave of immigrants who followed in Lewis and Clark's footsteps. In fact, as James Clifford argues, "only a few basic stories are told, over and over, about Native Americans and other 'tribal' peoples. These societies are always either dying or surviving, assimilating or resisting" (Predicament 242). The Tamástslikt Cultural Institute is an attempt by the Cayuse, Umatilla, and Walla Walla tribes to reclaim their stories and traditions, tell the tale of the "settlement" of the West from their perspective, and expand the history of their people beyond the popular narratives about Native Americans which persist in mainstream culture. 
As is the case with many other types of museums and cultural centers, Tamástslikt attempts to simultaneously tell the story of a people and invite the audience to better understand a culture. What is unique about this particular museum is the fact that, since oral traditions are an integral part of the tribes' cultures, narrative becomes more than a means for sharing culture. The tribes' stories are the culture, and the Tamástslikt Cultural Institute is designed and implemented in such a way as to invite the visitor to experience the culture of the tribes through their stories. As Clifford Trafzer explains, "stories provide texts through which outsiders may enter into a native world and become familiar with the ideas, values, lessons, characters, places, and knowledge important to specific native peoples" (16). Narratives dominate the experience at Tamástslikt. The meta-narrative about the history and modern-day life of the Cayuse, Umatilla, and Walla Walla people is constructed through an intricate web of shorter narratives about tribal life which are woven into the various exhibits. This web of stories simultaneously constructs culture and challenges popular narratives, such as that of the Lewis and Clark expedition.

The stories of the tribes succeed rhetorically in the extent to which they can induce visitors to perform, to give the viewers the illusion of experiencing the culture first-hand by making the tribal narratives part of their embodied experience. Performance is inherent in most modern museums, since, as Barbara Kirshenblatt-Gimblett observes, "[e]xhibitions are fundamentally theatrical, for they are how museums perform the knowledge they create" (3). However, Tamástalikt takes the theatricality beyond the creation of exhibits by casting the museumgoer in the role of "insider" to the culture. Visitors are asked to take on the role of amateur ethnographers. Through active engagement with the stories, the hope is that the audience will come to a better understanding of the culture of the Cayuse, Umatilla, and Walla Walla peoples. Tracy C. Davis notes that museums like Tamástslikt "promote self-reflection and a conscious performance by the visitor of the meaning of the place" (16, original emphasis). 
Tamástslikt invites performance on the part of the audience, and the rhetorical appeals of the various exhibits in the museum depend heavily on their ability to evoke such visceral responses.

The stories of the tribes not only bring the visitor into contact with the culture, but they also serve as a form of oppositional discourse or a counter-narrative by inviting visitors to question and perhaps revise their perspective on historical events. Richard Morris and Philip Wander explain that "the degree to which the dominant society has displaced tribal identities in favor of the 'Indian' has at times been so severe that Native Americans have become unrecognizable" (165). In taking ownership of their story, the tribes reject the "Indian" stereotypes of the mainstream culture and demonstrate how narratives can become an instrument of change. The stories told at the Tamástslikt Cultural Institute also illustrate the clear connection between narratives and power. As Ivan Karp and Steven Lavine note, "decisions about how cultures are presented reflect deeper judgments of power and authority and can, indeed, resolve themselves into claims about what a nation is or ought to be as well as how citizens should relate to one another" (2).

Popular stories about the "settlement" of the West reflect a specific perspective and power dynamic. The Pacific Northwest, in particular, is a region dominated by the mythic tales of people traveling great distances and overcoming great hardships in the quest for a better life. Harmon explains the appeal of this dominant narrative about the settlement of the Northwest when he notes that the Oregon Trail story often becomes a tale of "a providential trek through which 'pioneers' endured 'mortal danger' and 'extreme hardship' so their descendents could enjoy freedom and abundance" (118). The dominant stories about the settlement of the Northwest become, in their frequent retellings, the ultimate "human vs. nature" conflict. The ability of people to rise up in the face of great obstacles is a common motif in these tales, and victory over a wild and untamed environment is what the stories too often celebrate. Unfortunately, in many retellings Native Americans become just another part of the "natural 
forces" against which the white settlers had to persevere. As Morris and Wander contend, "the westward movement across this continent transformed the suppression of Native Americans into a national duty, if not a sacred obligation" (164).

The presentation of a counter-narrative at Tamástslikt poses a direct challenge to the pervasive tales of westward expansion and settlement. According to Michael Peters and Colin Lankshear, counter-narratives can be defined as stories which call into question 'the 'official' and 'hegemonic' narratives of everyday life: those legitimating stories propagated for specific political purposes to manipulate public consciousness by heralding a national set of common cultural ideals" (2). The story of the settlement of the West has become a significant element in the development and maintenance of "a national set of common cultural ideals," and Tamástslikt casts doubt on the universality of such ideals. The stories of tribal life presented at the museum have not been a part of the "official" stories because they damage the fidelity of those narratives. After all, if the West was already "settled," then how can it fairly be described as a "wild" and "untamed" land against which the pioneers had to struggle?

This analysis examines the constituent elements of the meta-narrative about the Cayuse, Umatilla, and Walla Walla tribes as it is presented at the Tamástslikt Cultural Institute, with a particular focus on the relationships among narrator, audience, and story. Four specific elements of the Tamástslikt narrative are critiqued: time, space, text, and artifacts. The analysis and discussion of Tamástslikt that follows is based on personal visits to the museum, newspaper and magazine accounts of the exhibits, and promotional materials distributed by the tribes. In addition to discussing specific narrative elements of the museum experience, this essay will also address the following issues:

1) Do the exhibits at Tamástslikt effectively demonstrate the existence of the Cayuse, 
Umatilla, and Walla Walla tribes as a dynamic and evolving culture? How does the use of some of the "traditional" forms of display common in other museums help or hinder this process?

2) Do the stories presented by the tribes lead visitors to question stereotypical views of Native Americans? How does the focus on shorter narratives throughout the exhibits contribute to this goal?

3) Is the overarching narrative presented by the tribes an effective counter-narrative to the popular histories about the exploration and settlement of the Pacific Northwest?

Given the ephemeral nature of the museum experience, the goal of this analysis is not to provide final answers to the aforementioned questions. Tamar Katriel reminds us, "museums, as privileged houses of memory, have a story to tell. But in the final analysis, the meanings of the story that arise in actual museum encounters are forever in flux" (160). Although a critical analysis of the narrative structure can serve to "fix" the meanings of the museum encounter, such an analysis proves useful as a means for better understanding the form, structure, and techniques behind stories which attempt to challenge popular accounts of the settlement of the West.

\section{Narrator}

Stories are alive with spirit, living memories of people, places, and things that are, at their core, sacred bodies of knowledge. Those who share the stories-storytellers--are honored members of native communities because they keep the stories in motion at each telling. (Trafzer 9)

In contrast to other museums, the presence of a narrator is an important feature of the Tamástslikt Cultural Institute. Upon entering the museum, members of the tribes sit behind a desk in the lobby area to collect admission fees and answer any initial questions. After passing through the door to the exhibit halls, however, the tour becomes self-guided. There are no human guides to serve the function of storyteller; instead, the narration is handled largely by a character 
named Coyote, "a kind of all-seasons trickster within the tribes' mythologies" (Graff). Since an important function of Tamástslikt is to share the tribes' history and perspective, all of the members of the tribe serve as storytellers to a certain extent. In fact, most of the shorter narratives that help to construct the overall story about the life of the tribes consist of written accounts, audio recordings, and videotaped stories from specific tribe members. However, Coyote serves as the voice of the tribes in their attempt to tell their overall story and is therefore cast in the role of storyteller for the meta-narrative.

In serving as a voice for the Cayuse, Umatilla, and Walla Walla peoples, Coyote shares their point of view and attempts to establish a relationship with visitors. As a trickster figure, Coyote is uniquely equipped to handle this task. The tribal members describe themselves on the Tamástslikt web site as "a small group of people who have maintained our traditional song, dance, art, language, clothing, religion, and food, despite significant events and changes in our lives." Bobbie Conner, tribal member and director of Tamástslikt, further explains the overall point of view of the members of the tribes when she states, "From our perspective, the West wasn't wild. . . The settling of the West, from our perspective, was the unsettling of our lives" (qtd. in Calos). Coyote is well suited to share this perspective, as the trickster has the "tendency to cross the boundaries of social and natural conventions, thus simultaneously challenging and highlighting them" (Ames 166). As an important figure in tribal mythology, Coyote can simultaneously speak for and about the people of the Cayuse, Umatilla, and Walla Walla tribes. The Confederated Tribes of the Umatilla Indian Reservation web site describes Coyote as "A main character in many stories of the Columbia Plateau tribes" ("Legends"). In addition to his cultural significance within the mythology of the tribes, Coyote is also well cast in the role of narrator because the displays at the Tamástslikt Cultural Institute require the visitor to frequently shift perspective or cross temporal and spatial boundaries. 
The "Coyote Theater" serves as the general introduction to the museum, and it is a space where visitors witness a "multimedia storytelling experience in a teepee-like setting complete with fire pit" (Nicholson 31). The first of a series of placards featuring Coyote appears at the entrance to the Theater. The placard has a "shadow" image of Coyote standing upright with his face upturned. Coyote has a prideful look about him. The text on the placard, serving as the voice of Coyote, invites the visitor to take on the trickster perspective by explaining, "I have important work for you .... For all the good things you do, you will be honored and praised. . . But for the foolish and mean things you do, you will be laughed at and despised. ..." A soft orange light illuminates the text and the image of Coyote from behind. Although the images of Coyote and the words change throughout the exhibits, all of them share the common design elements of the shadow images accompanied by text. Coyote is never presented in a fully realized form. In keeping with the shifting nature of the trickster, he is an enthymematic narrator. Just as in a traditional enthymeme (a syllogism in which one of the premises is implied or missing), Coyote's likeness is implied in the images displayed at Tamástslikt. The audience is invited to participate in the construction of Coyote's character by providing the missing visual information. This allows Coyote to be, as another placard at the entrance to the Theater explains, simultaneously "brave and foolhardy, considerate and conceited . . . a hero and a scapegoat." Trafzer notes that in the stories of many of the tribes of the Pacific Northwest, "Coyote embodies both the positive and negative powers of creation. At times he is a creator, protector, and dreamer. He sets many things into motion and makes things the way they are today" (21-22).

Coyote possesses supernatural abilities, and his voice, along with the lighting and sound effects in the Theater, make it possible for the audience to experience these powers. The Theater is a small "theater in the round" performance space with seating for approximately thirty. The space has the initial appearance of a planetarium, and a faux campfire sits in the center of the space. As noted previously, the Theater is "designed to resemble the interior of a mythic grand 
teepee" ( $\underline{\text { Tamástslikt)}}$. The story begins with a blackout to complete darkness, followed immediately by a few seconds during which a faint glow of light projects from the embers of the fire and the stars overhead. The story is a creation tale about Coyote, the ultimate teacher and trickster, who saves all of the plants, animals, and people of the world from a monster. Coyote is not the creator in this story, but he is the hero of the tale. The story is told with recorded voices, music, lighting effects, sound effects, and slides.

Coyote appears on the ceiling as a shadow image surrounded by orange light, in keeping with the theme established by the placard outside the Theater's entrance. The automated lights give Coyote the ability to "move" throughout the space, and his image dances across the ceiling throughout the show. Visitors also hear Coyote's voice for the first time in this space, and given the creative and mischievous nature of the trickster, a theater makes for an appropriate meeting place. Howling noises are briefly heard at first; then, Coyote begins to speak. He has a highly animated young, male voice. Coyote's tone is one of a storyteller attempting to captivate a room full of children. He exaggerates emotions throughout and brings a sarcastic, yet jovial tone to the narration. The story has humorous moments; Coyote loses his eyes at one point and even passes gas with an appropriate sound effect to accompany the act. The story establishes a relationship between narrator and audience, provides the visitor with a first glimpse of the tribal perspective and the importance of stories in the culture, and attempts, through humor, to establish in the minds of the visitors a level of trust and credibility in Coyote as a narrator. The presentation in the Coyote Theater establishes Coyote as a voice for the members of the tribes, and he continues in this role throughout the exhibits. The Theater is the first and last place where visitors hear Coyote's voice, but his presence is felt throughout the museum in the form of placards placed strategically throughout the exhibit halls. 
Museums were once defined by their relationship to objects: curators were "keepers" and their greatest asset was their collections. Today, they are defined more than ever by their relationship to visitors. (Kirshenblatt-Gimblett 138)

The narrative of traditional tribal life, customs, and adaptation presented at Tamástslikt is directed at multiple audiences, but the tribes seem to focus in particular on visitors who come to the museum with stereotypical views of tribal life. As Tamástslikt director Bobbie Conner explains, "We would like to be perceived as dynamic, evolving, healthy people... . That's not exactly what people expect to see when they visit a reservation" (qtd. in Egan). The tribes' desire to reach this particular audience is also evident from statements on their web site. For instance, the following text is used on Tamástslikt's web site to convince visitors to see the museum: "Experience traditions that have sustained our people for generations. Learn why we have survived for more than 10,000 years. Discover why we will never fade." Overall, the exhibits at Tamástslikt assume that visitors come into the museum with little accurate knowledge of tribal history and life.

The name of the museum is also reflective of the type of audience the tribes expect. The word "Tamástslikt" means "interpreter" in Wallulapum, the Walla Walla language, and with the Coyote Theater as the first stop for visitors, the museum invites the audience to take on an interpretive role from the outset. The Coyote Theater, like many of the other exhibits throughout Tamástslikt, allows visitors to bring much of their own knowledge, experience, and even stereotypes to bear in their attempts to understand the tribal perspective. As is the case with all museums, audience members always have the ability to define the exhibits in their own terms. Some of the exhibits at Tamástslikt are unique, however, in the extent to which they offer the audience extra leeway when it comes to imposing their own perspectives.

The longhouse, a central feature of the portion of the museum focusing on tribal history, is a prime example of the way Tamástslikt allows visitors to define the experience in their own 
terms. The longhouse is a dwelling, approximately 35 by 15 feet, which is designed to provide a feel for the housing that was typical for the tribes for many centuries. Visitors can enter the longhouse, where they find a faux dirt floor and benches all around the interior walls for seating. Inside, recorded voices share tribal stories on a wide range of topics. A placard in the longhouse reads, "Ancient myths, legends, and oral teachings were important sources of human knowledge. They constitute some of our oldest and most sacred possessions." The stories run continuously, and visitors can enter or exit at their leisure. The audio speakers are set up in such a way that the visitor gets the impression that the storyteller is sitting in the room, and the sound is directional so that, when a new story begins, it comes from a different location in the longhouse.

The stories in the longhouse are about the origins of religious beliefs, the creation of natural phenomena (like area waterfalls), and moral lessons. There is a wide range of diversity in terms of the age, social position, and gender of the narrators of the different stories, and each story lasts approximately one minute. A few of the stories start off in native dialects, and some are mixed with the sounds of drum music, chants, and other songs; many are accompanied by nature sounds in the background. Some of the stories feature Coyote as a primary character. For instance, one story describes Coyote's role in the creation of a local geological feature called "Elephant Rock." Another tale focuses on a boastful young man who was wrestled to the ground by a bear. One tale even speaks to the power of storytelling directly when the narrator, an elderly woman, explains that she "learned religion from grandma's songs and stories." The moral lessons contained within these tales are usually made explicit at the end of the stories, with phrases such as "always do as you are told" and "never brag because animals can hear you." A placard in the exhibit explains that, for the people of the tribes, "Every storytelling [is] an occasion for learning."

The longhouse exhibit shows the degree of control the audience has over their experience at Tamástslikt, but it also demonstrates how shorter narratives are used to help construct the 
meta-narrative about tribal history and life. In the longhouse, each visitor can get a sense for what it might have been like to sit in a dwelling like this and listen to others share stories. Of course, the extent to which the visitor immerses herself or himself in this experience is outside of the control of the members of the tribes, but the audience is afforded the ability, should they choose, to literally sit in on a powerful recreation of the lived experience of tribal ancestors. As Kirshenblatt-Gimblett notes, "live displays . . . create the illusion that the activities you watch are being done rather than represented, a practice that creates the effect of authenticity or realness" (55). With the wide range of topics covered in the shorter narratives, audience members who choose to sit and listen also experience some of the themes, morals, and values (live in harmony with nature, always be yourself, do what is best for the community) that are further developed and emphasized throughout the remaining exhibits.

Although the person who knows little about the tribes and their heritage might be the primary audience, the exhibits are also directed at the tribal members themselves. Tamástslikt is as much a vehicle for perpetuating the values and beliefs of those already living within the culture as it is a means of educating outsiders. There is a clear sense that Tamástslikt serves to reinforce and, perhaps to some extent, recreate a sense of tribal identity. In fact, a placard at the entrance to the first main exhibit hall mentions this goal directly when it states, "As our children listen to the deeds of tspilyáy (Coyote) and of times past, our untold story also begins." In addition, language courses, where students can study the Walla Walla, Umatilla, and Cayuse/Nez Perce languages, are offered at Tamástslikt. Tribal employees are allowed to take one hour per week from their normal work schedule to participate in these language programs. Mia Nicholson also notes that the facility includes "a repository of tribal artifacts, records and ceremonial effects as well as an educational center devoted to conveying a complete and accurate account of tribal tradition and history" (31). Members of the tribes are allowed to store family heirlooms and artifacts at Tamástslikt, and in this way the museum actively participates in the lives of tribal 
members as a sort of tribal historical society. Finally, the exhibits at the museum, particularly those near the end of the tour which focus on the future of the tribes, are directed as much at the younger members of the tribe as they are at the outsider. Not only are these displays replete with messages about the importance of continuing tribal practices and traditions, but the importance of educating the next generation is also a consistent theme. For instance, a photo display in the final exhibit hall, titled "We will never fade," features close-ups of the hands of people engaged in tribal crafts such as beadwork, weaving, digging roots, and flint knapping. The tribal elders view their own people as an important audience to reach because they know that the narrative about the tribe has the potential to transform how even their own people view the culture.

\section{Story}

The mode of installation, the subtle messages communicated through design, arrangement, and assemblage, can either aid or impede our appreciation and understanding of the visual, cultural, social, and political interest of the objects and stories exhibited in museums. (Karp 13-14)

The main story Tamástslikt tells is one of tribal origins, traditions, adaptation, survival, and hope. It is a narrative that spans thousands of years and, with such a range of time to cover, some elements obviously are emphasized at the expense of others. Tamástslikt is designed both to pique the interest of visitors by highlighting important tribal events and traditions and to make visitors question their interpretations of historical events. As is the case with other museums or cultural centers, the story is told through a combination of artifacts, models, dioramas, audio cues, video clips, and more experiential exhibits like the previously discussed Coyote Theater and longhouse. In the analysis that follows, four elements of the narrative structure of the Tamástslikt story are critiqued: time, space, text, and artifacts. An examination of these elements demonstrates the way the counter-narrative is structured and reveals some of the tactics the tribes use in their attempt to challenge the collective memory of the dominant culture. 
Time

After the general introduction provided in the Coyote Theater, visitors are directed toward the main exhibit halls. Tamástslikt is divided into three major areas labeled "we were," "we are," and "we will be." Although the museum follows a basic chronological structure, which essentially falls into a "past," "present," "future" format, the decision to avoid these terms is significant. The use of the labels "we were," "we are," and "we will be" is a direct way for the tribes to reject the logic that says that their cultures are part of the past. Instead, this seemingly subtle language choice is an attempt to demonstrate that the past is contiguous with the present and that tribal traditions are very much a part of the ongoing stream of life of the tribes. With each retelling, a story becomes "present" again in the consciousness of the listeners, and in a similar fashion the past is more "present" to the listener when it is labeled (through the use of the word "we") as something contiguous with the present. As Feldman explains, "Native American notions of 'cultural preservation' are based more upon living their cultures and restoring them to the practice of daily life as opposed to merely documenting traditions, stories, and language" (218). The way time is defined and used in the museum is important for the tribes because, from their point of view, who they were in the past is an integral part of their identities in the present.

The first main exhibit hall, "we were," is an attempt to describe the traditional lifestyle of the tribes, including hunting and gathering practices, dress, the introduction of horses into the culture, and the ties to the land. The Tamástslikt web site describes this portion of the museum as one which depicts "the seasonal lifestyle that was typical on the Columbia Plateau for centuries." This is the most extensive exhibit hall in the museum, and it takes the visitor all the way from stories of tribal origins to the early 20th century when the tribes were forced onto reservations. From the standpoint of time, in this portion of the museum it is significant that the story is framed as a tale of a living people as opposed to an extinct culture. For instance, part of the "we were" exhibit presents artifacts like blankets, fishing nets, arrows, and moccasins in a series of 
glass cases, but the cases themselves are framed by a wood structure to make them into a shape of a "seasonal round" (a circular tribal dwelling) adjacent to the longhouse. Although the glass cases evoke a sense of the past, they are intimately connected with ongoing cultural practices through their quite literal framing within the context of a village. The sharing of techniques for constructing tribal dwellings is an important part of the tribes' current efforts to preserve traditional practices.

The second major exhibit area, "we are," discusses what tribal life is like today. A placard in the middle of this exhibit reads, "Our encounter with humanity continues to unfold. As natítayt (the people), we are an evolving culture and coexist in two divergent worlds. Both individually and collectively, we are adapting to contemporary American life." Several video montages are used to help paint a picture of contemporary tribal life. Some topics covered in this portion of the museum include "the importance of veterans and the warrior tradition, extensive efforts to restore salmon, modern multi-cultural lifestyles, development of a tribal economy, [and] participation in celebration events" (Tamástslikt). The process of returning salmon to the Umatilla River, a project which is explained through pictures and a large map and diorama, is discussed in detail. The display shows how the tribes have set up a successful fish trap-and-haul operation to help ensure safe fish migrations during low-flow periods in the river. Another display discusses the ongoing process of revitalizing the tribes' native languages.

A central feature of the "we are" exhibit is a small theater, with seating for approximately twenty audience members, where a short movie featuring interviews with members of the tribe runs continuously. The movie provides a candid look at tribal members practicing age-old traditions such as smoking salmon in an earth oven. The film also clearly demonstrates the way the tribes have combined the traditional with the modern; for instance, clips are shown of tribal members driving pick-up trucks full of supplies for use in the salmon smoking process. Beneath these stories of tradition and adaptation, however, there are ongoing hints about how the tribes 
have faced many obstacles in their efforts to perpetuate their cultural practices. In a brief clip near the end of the movie, one woman explains that the tribes were "tricked out of most of our land [and] the creator's rivers were dammed up." She concludes "maybe Coyote was trying to teach us a lesson." The end of the film, however, does offer some hope. The movie concludes with the statement, "Coyote is still here, still teaching; we have a lot more to learn. Listen." The references to Coyote throughout the film demonstrate his ability to transcend temporal boundaries and further emphasize the continuity between past and present cultural practices.

"We will be" is the third major exhibit area at Tamástslikt. It is by far the smallest in terms of the amount of content, but the absence of extensive artifacts, displays, and dioramas also signals that the future is akin to a blank slate. The central feature of this exhibit hall is a large photo of members of the tribes during the 1906 "Frontier Days" in Walla Walla. A sequence of lighted quotations, reminiscent of the moral lessons offered at the end of each of the tales in the longhouse, flashes on a white wall just above the picture. Some of the statements are general statements about tribal values ("We live with nature and all things are connected"), while others are commands (“Know your language, know your religion, know your foods”). The juxtaposition of the 1906 photo and the forward-looking quotations once again emphasizes the notion that the past and the future are contiguous. The "we will be" exhibit also features a looping video montage of interviews with various members of the tribe regarding their views on the future. The tribal youth are a focus of this montage, in the sense that many interviewees discuss the importance of preserving traditional ways, preserving the languages, and passing on this knowledge to the next generation. Of all the exhibits at Tamástslikt, the "we will be" exhibit seems to be most directed toward reinforcing the cultural values of the tribal audience.

Coyote is the narrative bridge who connects the various stories about tribal life across the exhibits and across the three different "times" and makes them into one continuous story. Placards with Coyote's image and "voice" (modeled after the previously described placard 
outside of the Coyote Theater) appear between the three major exhibit halls. Weaving the narrator throughout the three exhibit halls helps to emphasize the contiguous nature of time and show once again that the past, present, and future are one. Michael Ames explains why such an emphasis is necessary when he states, "non-native people are still struggling to come to terms with the fact that the past can be continuous with the present, that the 'traditional' may be part of the 'modern'-as in 'living traditions' - and that Indians who wear Adidas running shoes, drive pick-up trucks, and carve with the aid of power tools, are still no less Indian for all that" (159). The story of the tribes as it is told at Tamástslikt poses a challenge to conventional assumptions about time, particularly with regard to the way time has historically been applied to the life and traditions of the tribes. In the popular stories of westward expansion, the Cayuse, Umatilla, and Walla Walla tribes are part of the past. The story at Tamástslikt effectively presents these tribes as a part of the present and future.

Space

The tribes' story centers on space both as a thematic element and an organizational strategy. With the influx of settlers, the ownership of space became an integral part of the tribes' history, and various exhibits at Tamástslikt attempt to describe this struggle for space. As in most museums, the use of space and environment also becomes an integral part of the meta-narrative about the life and experiences of the tribes. The museum walls, the lighting, and even the sound effects all contribute to the construction of the space and provide a context for the story of the tribes. Finally, the placement of Tamástslikt on the reservation is also significant in terms of the tribes' use of space. Tamástslikt is located at the foot of the Blue Mountains, with large windows facing east toward the mountain passes used by wagon trains so many years before. Conner explains the importance of space to the tribes' narrative when she states, "Our story is not separable from the land. It's a story of place. ... It's important for people to come here, to embrace the story in the place that it occurs" (qtd. in Nicholson 30). 
The treaty of 1855, which established the reservation, is mentioned frequently throughout the exhibits, and this particular event holds great significance in terms of the tribes' use of space. Before the 1855 treaty, the "three tribes inhabited 6.4 million acres in Southeastern Washington and Northeastern Oregon" ( $\underline{\text { Tamástslikt)} . ~ A f t e r ~ t h e ~ t r e a t y, ~ t h e ~ t r i b e s ~ w e r e ~ c o n f i n e d ~ t o ~ " a ~ 500,000 ~}$ acre reservation that was then reduced by more than half" ("Treaty"). One particular exhibit at Tamástslikt takes visitors through the process that led to the tribes living on the current reservation. The exhibit is a descending wooden ramp that starts with placards describing the initial negotiations with white settlers at the top. The ramp carries visitors over a faux natural landscape, designed to illustrate the impact of trail trash on the life of the tribes. The placards are placed on top of wooden boxes (presumably bits of trash left by settlers), and other evidence of the mass migration (such as a washing board, bottles, broken pottery, a doll, wagon wheels, tools, and a small chalk board) appears scattered on the ground surrounding the boxes. The middle of the ramp covers various conflicts during the process of developing the treaties, and the exhibit concludes at the bottom of the ramp with a placard reading, "In the end, the plateau tribes forfeited 45,000 square miles of aboriginal lands to the U.S. government. Many became homeless." The end of the ramp also vividly illustrates another low point in tribal history: the Indian education program. A life-sized photo of 50-75 Indian children at the Chemwa "Indian Training School" in Salem, Oregon appears at the bottom of the ramp. The descent down the ramp, from a high of tribal control of all 6.4 million acres to a low of ceding most of this territory and the education of their children to the federal government, provides visitors with a visceral experience by allowing them to feel a true low point in tribal history.

In addition to specific exhibits focusing on the creation of the current reservation space, the overall design of the museum and the use of other effects help to create an environment that advances the story and invites visitors to experience the tribes' cultures. The building itself is "a simple, vaulting, post-and-beam structure clad with varying widths of cedar siding to evoke the 
fabriclike, tule-mat walls of the tribes' traditional dwellings" (Graff). A large mural of the Columbia River, appearing rough and untamed as it must have looked in the days before it was dammed, is featured prominently in the lobby. The walk down to the Coyote Theater to start the tour features large windows looking out on the landscape of the nearby Blue Mountains, giving visitors a glimpse of the land that has defined the tribes' cultures. As visitors proceed through the Coyote Theater and the various exhibit halls, they move in a circular, counterclockwise fashion. The Tamástslikt web site explains that this "circular exhibit space ... symbolizes the Tribes' worldview of the cyclical continuum of time." Nicholson notes that the counterclockwise motion of the tour is "in keeping with many aspects of tribal tradition" (30).

Sound effects are also used frequently throughout the exhibits to help create a sense of space. The aural environment is particularly pronounced in the "we were" portion of the museum, where directional sounds help describe early life for the tribes; for instance, the sound of running horses is incorporated in an exhibit on the importance of horses in the tribes' culture. The exhibit focusing on "Indian education" is accompanied by the sounds of busy schoolchildren, and an exhibit on the impact of missionaries and Western religions on the tribes features the environmental sounds of a church bell and parishioners singing hymns. Although these sound effects are not the primary medium for conveying a sense of space in these exhibits, they help to situate visitors in a particular environment.

Text

Speech is sacred. Conversation, dialogue, talking things over--all enter into the mystery of life itself. For oral cultures, generally, and for marginalized people, especially, the spoken word possesses the power of community. (Morris and Wander 186)

Textual information provided throughout the exhibits becomes, in conjunction with the temporal and spatial cues, a means of conveying the significant events in the ongoing story of the 
tribes. Although the text in many museums can create a sort of distance between the visitor and the creator of the tale, the placards and other pieces of textual knowledge provided in Tamástslikt are designed to create a more intimate relationship between storyteller and listener. As mentioned previously, Coyote provides a narrative bridge throughout the exhibits, but even words that do not come directly from Coyote are crafted in such a way as to invite a conversation or dialogue. Tamástslikt is not simply telling visitors a story; rather, visitors are invited to participate actively in the creation of the ongoing story of the tribes.

One textual tactic used throughout the exhibits is the continued use of the first person plural pronoun "we." As previously discussed, the main exhibit halls are labeled "we were," "we are," and "we will be," and the use of terms like "we" and "our" is also pronounced in the placards accompanying all of the artifacts, dioramas, and videos. In the "we were," exhibit, for instance, two of the placards read in part, "Later, we moved to the high mountains to pick berries and hunt deer and elk," and "Our ancestors established many fisheries." Another section in the same exhibit hall states, "The use of visual imagery expressed who we were and where we came from." While the use of these pronouns is a relatively simple tactic, it has the effect of connecting the present day tribal members more directly to events in their past. The cumulative effect of this language is to suggest to the visitor, in a powerful way, that the Cayuse, Umatilla, and Walla Walla tribes are still living, breathing cultures.

The text surrounding the exhibit detailing the arrival of Lewis and Clark is particularly interesting in terms of the relationship established between visitor and storyteller. The preface to the exhibits discussing the influx of immigrants is titled, "They arrived from the east." A placard featuring Coyote appears at the beginning of this section, with Coyote hunched over in a defensive posture, and the cautionary words, “... white people with hair on their faces will come from the rising sun. You people must be careful." Although the language is strong in some of the vivid descriptions of the treaty process, Indian education, and other brutal changes imposed upon 
the tribes, the specific words used to describe the initial encounters with white immigrants are somewhat neutral and more subdued in tone. Instead of providing accounts of harsh conflicts between the tribes and the settlers, the focus is more on describing how the tribes adapted to the changes brought about by the influx of people. For instance, one placard in the exhibit explains, "Although sometimes colored by frontier prejudice, encounters between the immigrants and the tribes were mostly friendly and beneficial."

The exhibit on the immigrants, perhaps in an attempt to better engage visitors who might be descendants of those initial settlers, also places blame for the migration on business interests and appeals to environmental concerns. The placard at the start of the exhibit reads, "In 1805, the plateau was forever altered when explorers Lewis and Clark landed their canoes on the banks of the Columbia River. It was not long before American and British fur companies were scrambling to stake their claims." Although Lewis and Clark "altered" the landscape, the fur companies are positioned as the imposing force by "staking" their claims to the land. Another tactic for engaging the visitors in the story of the migration of settlers is to focus on environmental concerns. A placard near the end of the exhibit reads, "The impacts of massive migration became clear as each year went by. We saw a visible ecological imbalance in the land. Grazing lands began to diminish. Water holes become polluted. Game animals became more scarce. Trail trash littered the landscape." In this particular passage, the "impacts" of the migration are described without squarely placing blame on any one person or group of people.

\section{Artifacts}

Exhibitions of social history are driven by interpretive ideas and are usually organized as narratives. As a result, objects are not made the primary focus of exhibits but retain significance as corroborative evidence. (Lavine 152)

The use of artifacts and other objects in Tamástslikt is similar in many ways to what a visitor might encounter in any other museum. The "we were" exhibit includes objects like 
clothing, arrowheads, baskets, pipes, and blankets. The main difference in Tamástslikt is that the museum always contextualizes these objects within the broader narrative of the life of the tribes. Conner explains why the tribes do this: "A lot of people are interested in representing the artifacts of our culture: their use, how they were constructed, the craftsmanship. But artifacts are only a representation of the living culture. We're interested in both" (qtd. in Nicholson 30). To the extent possible, the museum displays the objects in such a way as to demonstrate their ongoing connection to cultural practices. Of course, the artifacts displayed also serve as "props" that aid in the construction of the overall narrative of tribal life. There are certainly sections in the museum where one still feels very much like these objects are on display, and environmental variables like glass cases and lighting serve to emphasize this "display" ethic. Throughout the museum, however, there are several notable instances where objects are used in such a way as to diffuse the artifice of "display." In these exhibits, objects push visitors toward feelings of authenticity that come with a genuine understanding of the tribes' cultural perspective.

The exhibit on "Indian Education" is one location where objects are used in such a way as to demonstrate this cultural connection. Visitors enter this exhibit and find themselves in a crude reproduction of a one-room schoolhouse. Desks are lined up in neat rows, and, as previously mentioned, the chatter of schoolchildren surrounds them. Class photos of students standing outside their schools are displayed, and various objects like books, pens, paper, and other learning tools are spread throughout the exhibit. A placard at the center of the schoolroom reads, "Our children experienced hardship at these schools. Indian students were punished if they were caught speaking their native language." In this particular exhibit, the cumulative impact of all of the objects attempts to give the visitor a clear sense for what it must have felt like to be a student in one of these schools. It is an area where the visitor can easily take the imaginative leap from viewing the object by itself to seeing the object as it was used in the culture. It is also an area where the open nature of the narrative allows room for misinterpretation. Despite all of the 
textual cues, a visitor who is focused squarely on the objects could potentially read this exhibit as a "cute, antique schoolroom." Obviously, this is not the feeling that the tribes want visitors to have, but the open nature of the story allows for such reactions.

One of the final exhibits in the "we were" portion of the museum achieves this connection between the objects and cultural practice in a different way. The exhibit is titled "sikemnúut" or "horseless," and it focuses on "the proud tribal tradition of horse breeding" (Graff). The only object on display in this particular exhibit is a pyramid of dog food cans stacked in the center of the room. A plaque at the front of the stack of cans explains that the tribes' last horses were rounded up in the early 1900s by the federal government and shipped off to Portland, Oregon to be processed by a dog food company. It concludes with the statement, "The loss of our horses was devastating." The pyramid of cans is a curiosity at first, but the text accompanying the cans transforms them into a memorial of sorts. This graphic and startling representation of the absence of the horses, and the image that it provides of their final fate, has the potential to evoke a sense of empathy from visitors and create a clearer understanding of how it must have felt to endure such a loss.

Artifacts play a significant role in telling the overall story of the culture of the tribes at Tamástslikt. Although it seems contradictory to place objects that are an ongoing part of cultural practice on display, the careful framing of these objects within the broader narrative of tribal life helps to preserve their cultural context. For native people, who see living spirit in all tribal artifacts, the things that they make and build are culture. It is always possible for a visitor to reject the overall narrative of tribal life and thus view the artifacts on display as examples of primitive art devoid of cultural significance, but the narratives at Tamástslikt provide a means through which visitors can potentially "expand the aesthetic experience beyond [their] own narrowly culture-bound line of vision" (Price 93). 


\section{Conclusions and Implications}

The story about the Cayuse, Umatilla, and Walla Walla tribes presented at Tamástslikt paints a picture of a dynamic and evolving culture, particularly in contrast to museum displays created by non-Indian organizations. As Clifford notes, "The emergence of tribal museums and cultural centers makes possible an effective repatriation and circulation of objects long considered to be unambiguously 'property' by metropolitan collectors and curators" ("Four" 242). The message that the Cayuse, Umatilla, and Walla Walla people are actively participating in their cultures is an integral part of the meta-narrative, and it resonates throughout the exhibits. The tribes do, however, use dioramas, placards, objects, and other forms of display common to other museums. How effective, then, is the "repatriation" in this particular case? After all, as Katriel argues, "the transfer of objects and meanings into a museum involves their removal from the culture's ongoing stream of life, signaling their state of obsolescence even while marking their presence in the public eye" (22). Does the process of display, as Katriel contends, necessarily remove the objects shown from the culture?

As a "cultural institute," Tamástslikt aims to show that the objects on display are still very much a part of the tribes' "ongoing stream of life." The effort to make the connection between the objects of display and the ongoing cultural practice is by and large a successful one. With language courses and a storage facility for important cultural artifacts, Tamástslikt extends beyond the bounds of a typical museum with the aim of serving as a repository for cultural materials. The objects themselves and the language used to describe them also ask visitors to consider the artifacts as part of the ongoing cultural experience. The tribes have even found ways to reframe more "traditional" forms of display, like the previously discussed artifacts in the seasonal round, in order to cast them as part of an ongoing cultural dialogue between the past and the present. Finally, the overall framing of the museum experience with a narrative about Coyote helps to create a feeling of active engagement with the tribes' cultures. 
The meta-narrative about the tribes, as well as the shorter narratives provided in exhibits like the longhouse, at least have the potential to get audiences to question stereotypical views of Native Americans. Visitors bring different levels of knowledge and experience with them to the museum, so the potential for change varies from person to person. Certainly the design of the space, the unique framing of the different times in tribal history, and the presentation of textual cues demonstrate a cultural orientation specific to the tribes. There is no guarantee, however, that visitors will embrace or even recognize this specific cultural orientation. As Karp notes, "the audience has its ways of escaping control, from refusing to follow the exhibition plan to seeing their assumptions about identity confirmed in the design and arrangement of objects" (15, original emphasis). Visitors always bring their own assumptions about how best to audience the museum with them, and these assumptions can rather dramatically change the impact of some of the exhibits. The messages in all of the areas in Tamástslikt, from the "Indian education" exhibit to the "longhouse," can be dramatically altered or rejected by visitors depending on the interpretative frame they bring to the experience. Audiences are always free to reject the stories should they choose to do so, and when they do the museum experience could even reinforce existing stereotypes about Native Americans.

The caveat about audiences rejecting the stories aside, however, the meta-narrative presented by the tribes is an effective counter-narrative to the popular histories about the exploration and settlement of the Pacific Northwest. The tribes hope that at the end of the presentation in the Coyote Theater, "visitors are aware that the place they have entered is a tribal facility, a powerful place where their normal conceptions of events and history will be challenged and perhaps changed" ( $\underline{\text { Tamástslikt }) . ~ A l t h o u g h ~ t h e r e ~ i s ~ a l w a y s ~ t h e ~ c h a n c e ~ t h a t ~}$ individual audience members will reject the attempt to challenge their own accounts of historical events, the narrative as it is presented at Tamástslikt opens visitors up to the possibility for change. Tribal control of their own story is the primary reason that such a change is even 
possible, because a visit to Tamástslikt is, for many audience members, a first exposure to the Native American perspective on these particular historical events. As Marouf Hasian and A. Cheree Carlson explain, "collective memories are selectively chosen and highlighted to fit the needs of a particular social group. Ownership of 'history' then becomes a hegemonic device that controls our interpretation of the past and subsequent behavior in the future" (42).

As a trickster figure and an enthymematic narrator, Coyote is the ideal figure to share the meta-narrative of tribal life for all types of audiences. For the tribal audience, Coyote's presence in the museum brings to life a central character in Cayuse, Umatilla, and Walla Walla stories. William Bright contends that "the telling of Coyote stories still serves as a way of teaching traditional values - and, indeed, as a humorous way of asserting Native identity in the face of immense pressures" (182). For the native and non-native audiences, Coyote is presented in such a way as to allow visitors to read their own experiences into his actions. Coyote's presence is felt and cannot be ignored, yet it is not so overbearing or omnipresent as to restrict the audience's ability to bring their own interpretative frame to bear on the exhibits. In short, he is like a teacher who employs the Socratic method: Coyote's mission is to encourage learning and get the audience involved in the telling of stories.

Tamástslikt provides a venue for the presentation of an alternative interpretation of history. As a forum for sharing oppositional discourse, it has the potential to change the perspective of visitors. There is increased interest in viewing these types of counter-narratives of late, since "the number of tribal museums and cultural centers has climbed rapidly to about 300 nationwide" (Graff). This desire to better understand tribal perspectives might be fueled in part by postmodern thinking with its recognition of multiple perspectives and multiple histories. This sharing of oppositional discourse might also be increasingly popular because it challenges assumptions about identity. As a placard in the longhouse exhibit explains, "The natítayt (the people) believed that every living being was known as a story." Perhaps Coyote's ultimate lesson 
is that we can all come to a more complex understanding of history, culture, and ourselves by viewing our own life experiences in narrative terms. 
Works Cited

Ames, Michael M. "Cultural Empowerment and Museums: Opening up Anthropology through Collaboration." Objects of Knowledge. Ed. Susan Pearce. London: Athlone, 1990. 15873.

Bright, William. A Coyote Reader. Berkeley: U of California P, 1993.

Calos, Katherine. "Indian Exhibits Tell Different Tale: 'Discovery' Nothing New to Tribes." Richmond Times Dispatch 19 Jan. 2003: H2.

Clifford, James. "Four Northwest Coast Museums: Travel Reflections." Exhibiting Cultures: The Poetics and Politics of Museum Display. Eds. Ivan Karp and Steven D. Lavine.

Washington, D.C.: Smithsonian, 1991. 212-54.

---. The Predicament of Culture: Twentieth-Century Ethnography, Literature, and Art. Cambridge, MA: Harvard UP, 1988.

Davis, Tracy C. "Performing the Real Thing in the Postmodern Museum.” TDR 39.3 (1995): 1540.

Egan, Timothy. "Indian Reservations Bank on Authenticity to Draw Tourists." New York Times 21 Sep. 1998, late ed.: A1.

Feldman, Alice E. "Dances with Diversity: American Indian Self-Preservation within the Re-Presentative Context of a Non-Indian Museum." Text and Performance Quarterly 14 (1994): 210-21.

Graff, Randy. "In Tribal Museums, Indians' View of Their History Can Be Prickly." $\underline{\text { New }}$ Orleans Times-Picayune 7 Mar. 1999: 4B.

Harmon, Rick. “Editor’s Introduction.” Oregon Historical Quarterly 94 (1993): 117-20.

Hasian, Marouf, and A. Cheree Carlson. "Revisionism and Collective Memory: The Struggle for Meaning in the Amistad Affair." Communication Monographs 67 (2000): 42-62.

Karp, Ivan. "Culture and Representation." Exhibiting Cultures: The Poetics and Politics of 
Museum Display. Eds. Ivan Karp and Steven D. Lavine. Washington, D.C.: Smithsonian, 1991. 11-24.

Karp, Ivan, and Steven D. Lavine. "Museums and Multiculturalism." Introduction. Exhibiting Cultures: The Poetics and Politics of Museum Display. Eds. Ivan Karp and Steven D. Lavine. Washington, D.C.: Smithsonian, 1991. 1-9.

Katriel, Tamar. Performing the Past: A Study of Israeli Settlement Museums. Mahway, NJ: Erlbaum, 1997.

Kirshenblatt-Gimblett, Barbara. Destination Culture: Tourism, Museums, and Heritage. Berkeley: U of California P, 1999.

Lavine, Steven D. "Museum Practices." Exhibiting Cultures: The Poetics and Politics of Museum Display. Eds. Ivan Karp and Steven D. Lavine. Washington, D.C.: Smithsonian, 1991. 151-58.

"Legends and Oral Histories." Confederated Tribes of the Umatilla Indian Reservation. 2005.

Confederated Tribes of the Umatilla Indian Reservation. 6 June 2005 <http://www.umatilla.nsn.us/hist3.html\#legends>.

Morris, Richard, and Philip Wander. "Native American Rhetoric: Dancing in the Shadows of the Ghost Dance." Quarterly Journal of Speech 76 (1990): 164-91.

Nicholson, Mia. "Coming Home: Building the Tamástslikt Cultural Institute as a Labor of Love." Oregon Business Feb. 2001: 30-31.

Peters, Michael, and Colin Lankshear. "Postmodern Counternarratives." Counternarratives: Cultural Studies and Critical Pedagogies in Postmodern Spaces. Eds. Colin Lankshear, Henry Giroux, Peter McLaren, and Michael Peters. New York: Routledge, 1996. 1-39. Price, Sally. Primitive Art in Civilized Places. Chicago: U of Chicago P, 1989. Tamástslikt Cultural Institute. 17 May 2005. Confederated Tribes of the Umatilla Indian Reservation. 6 June $2005<$ http://tamastslikt.org>. 
Trafzer, Clifford E. Grandmother, Grandfather, and Old Wolf: Tamánwit Ku Súkat and Traditional Native American Narratives from the Columbia Plateau. East Lansing: Michigan State UP, 1998.

"Treaty Day Lunch June 9." Confederated Umatilla Journal [Pendleton, OR] 3 June 2004: 4. 